\title{
Outcomes using exhaled nitric oxide measurements as an adjunct to primary care asthma management
}

\author{
Richard S Hewitta, Catherine M Modrich ${ }^{b}$, Jan O Cowan ${ }^{a}$, G Peter Herbison ${ }^{a}$, \\ *D Robin Taylor
}

a Dunedin School of Medicine, University of Otago, Dunedin, New Zealand.

${ }^{b}$ Mornington Health Centre, Dunedin, New Zealand.

Received 4th May 2009; revised version received 14th June 2009; accepted 18th July 2009; online 3rd November 2009

\begin{abstract}
Background: Exhaled nitric oxide ( $\mathrm{F}_{\mathrm{ENO}}$ ) measurements may help to highlight when inhaled corticosteroid (ICS) therapy should or should not be adjusted in asthma. This is often difficult to judge. Our aim was to evaluate a decision-support algorithm incorporating $\mathrm{F}_{\mathrm{E}} \mathrm{NO}$ measurements in a nurse-led asthma clinic.

Methods: Asthma management was guided by an algorithm based on high ( $>45 \mathrm{ppb}$ ), intermediate (30-45ppb), or low (<30ppb) $\mathrm{FENO}_{\mathrm{E}}$ levels and asthma control status. This provided for one of eight possible treatment options, including diagnosis review and ICS dose adjustment.

Results: Well controlled asthma increased from $41 \%$ at visit 1 to $68 \%$ at visit 5 ( $p=0.001)$. The mean fluticasone dose decreased from $312 \mathrm{mcg} /$ day at visit 2 to $211 \mathrm{mcg} /$ day at visit 5 ( $p=0.022)$. There was a high level of protocol deviations ( $25 \%)$, often related to concerns about reducing the ICS dose. The \% fall in $\mathrm{F}_{\mathrm{E} N O}$ associated with a change in asthma status from poor control to good control was $35 \%$. Conclusion: An $\mathrm{F}_{\mathrm{E}} \mathrm{NO}$-based algorithm provided for a reduction in ICS doses without compromising asthma control. However, the results may have been influenced by the education and support which patients received. Reluctance to reduce ICS dose was an issue which may have influenced the overall results.

Trial registration: Australian Clinical Trials Registry \# 012605000354684

(C) 2009 General Practice Airways Group. All rights reserved.

RS Hewitt, et al. Prim Care Resp J 2009; 18(4): 320-327

doi:10.4104/pcrj.2009.00060
\end{abstract}

Keywords asthma control, exhaled nitric oxide, inhaled corticosteroid, primary care

\section{Introduction}

Using biomarkers to guide disease management offers the opportunity to improve clinical outcomes, particularly if changes in the biomarker are more sensitive and specific for disease activity than changes in symptoms. This is true for exhaled nitric oxide ( $\mathrm{F}_{\mathrm{ENO}}$ ), which is a surrogate measure of eosinophilic inflammation.' Importantly, eosinophilic airway inflammation is usually steroid-responsive, ${ }^{2,3}$ and FENO may be used to predict steroid responsiveness. ${ }^{4,5}$ Against this background, randomised trials have explored whether inhaled corticosteroid (ICS) dose adjustment based on $\mathrm{FENO}_{\mathrm{E}}$ will improve outcomes. ${ }^{6-10}$ Some of these studies have been reported after the present study was commenced. ${ }^{7,8,10}$ Overall, they have yielded inconsistent and somewhat disappointing outcomes, in contrast to proof-of-concept studies in which sputum eosinophil counts have been shown to improve asthma management. ${ }^{11,12}$ In one study, asthma control was maintained on significantly lower doses of ICS (40\% less) in patients whose requirements were based on $\mathrm{F}_{\mathrm{E} N O}$, compared to a group whose dose was adjusted using a symptom-based algorithm. ${ }^{6}$ In other recent studies, no significant differences in asthma control were achieved when FENO was added to well organised conventional asthma management, ${ }^{7,10}$ this may reflect the fact that regular contact with patients together with easy access to appropriate medications are more important than the use of a biomarker.

\footnotetext{
* Corresponding author: Professor D Robin Taylor, Dunedin School of Medicine, University of Otago, P.O.Box 913, Dunedin, New Zealand Tel: +64 34740999 Fax: +64 34776246 E-mail: robin.taylor@stonebow.otago.ac.nz
} 
Increasingly, asthma is being managed by nurse practitioners in association with primary care physicians. Local or international guidelines which focus on patient-reported symptoms form the basis for management, but it is recognised that symptoms are non-specific and multifactorial, and may be difficult to interpret. Assessing the need for changes in inhaled drug therapy can be challenging, and in theory at least, objective measurements of underlying disease activity, independent of symptoms, would be beneficial.

In a recent study, the feasibility of obtaining $\mathrm{F}_{\mathrm{E}} \mathrm{NO}$ measurements in primary care has been confirmed..$^{13}$ Here, we evaluated the utility of using $\mathrm{F}_{\mathrm{E} N O}$ levels in an unselected population of patients with a diagnosis of asthma in a primary care setting. The aims were two-fold: firstly, to assess whether an open FENO-based protocol - similar to, but less resourceintensive than those used in previous randomised controlled trials - could be applied in the primary care setting, and what the impact on asthma outcomes would be; and secondly, to evaluate the practical issues associated with using and interpreting $\mathrm{F}_{\mathrm{E}} \mathrm{NO}$ levels in a nurse-led asthma clinic.

\section{Methods \\ Subjects}

Patients with new onset asthma symptoms of six weeks' duration or longer or with previously diagnosed asthma were recruited. The setting was a primary care practice comprising 15,500 patients served by 11 general practitioners (GPs) in Dunedin, New Zealand. Patients with significant cardiac or other respiratory disease (including COPD), or other important co-morbidities were excluded. Smokers and recent ex-smokers ( $<6$ months) were also excluded due to the confounding effect of smoking on FENO measurements. ${ }^{14}$

\section{Study design}

This was an open, uncontrolled study designed to apply the findings of an earlier randomised controlled study ${ }^{6}$ in a primary care setting. At the initial assessment, inclusion and exclusion criteria were reviewed. For patients not taking ICS, each was commenced on inhaled fluticasone (Flixotide, GSK, Greenford, UK) at an initial dose of $250 \mathrm{mcg} /$ day via a spacer (Volumatic, GSK, Greenford, UK). For patients already taking ICS, they continued on the same drug in accordance with an equivalence protocol (see Table 1).

Patients were reviewed at three-monthly intervals for a total of 12 months (5 visits). At each visit, self-reported compliance with ICS therapy was ascertained and the need for any courses of oral prednisone was recorded. Asthma control was assessed on the basis of the "Three Questions"; i.e. "Over the last week 1. Have you had difficulty sleeping because of your asthma symptoms (including cough)? 2. Have you had more than your usual asthma symptoms during the day (cough, wheeze, chest tightness or
Table 1. Steps for ICS dosing. The conversion table provided equivalent doses for each of the inhaled corticosteroid and combination ICS/LABA preparations available in New Zealand at the time of the study.

Fluticasone (mcg) Budesonide/Beclomethasone ( $\mathrm{mcg}$ ) (Flixotide/Seretide)

(Pulmicort/Symbicort/Beclazone)

\begin{tabular}{ccccc}
\hline Step & $\begin{array}{c}\text { Total daily } \\
\text { dose }\end{array}$ & $\begin{array}{c}\text { Twice daily } \\
\text { dosing }\end{array}$ & $\begin{array}{c}\text { Total daily } \\
\text { dose }\end{array}$ & $\begin{array}{c}\text { Twice daily } \\
\text { dosing }\end{array}$ \\
\hline 0 & 0 & 0 & 0 & 0 \\
\hline 1 & 100 & 50 & 200 & 100 \\
\hline 2 & 250 & 125 & 400 & 200 \\
\hline 3 & 500 & 250 & 800 & 400 \\
\hline 4 & 1000 & 500 & 1600 & 800
\end{tabular}

breathlessness)? 3. Has your asthma interfered with your usual activities (e.g. housework, work/school)?"15 A zero score is highly predictive of well controlled asthma. ${ }^{16}$ Where one or more of these questions was answered "yes" then asthma was deemed to be not well controlled. A recent increase in short-acting beta-agonist bronchodilator use compared to usual was also used as a marker of suboptimal asthma control. An FENO measurement and spirometry were obtained.

Treatment was then adjusted according to the treatment algorithm in Figure 1. The algorithm specifically included options additional to ICS dose adjustment. The ranges for high, intermediate and low FENO levels were $>45 \mathrm{ppb}, 30$ $45 \mathrm{ppb}$ and $<30 \mathrm{ppb}$, respectively. These cut-points were based on data available at the time the study was designed. These indicated that levels of $>47 \mathrm{ppb}$ are associated with steroidresponsiveness ${ }^{5}$ or the potential for relapse in asthma control when ICS therapy is reduced or withdrawn, ${ }^{17}$ and that the upper limit of "normal" for patients with stable asthma is 33ppb. ${ }^{18}$ Thus $45 \mathrm{ppb}$ and 30ppb were chosen as cut-points. The dosing steps for ICS are shown in Table 1. At any visit, the patient's GP was permitted to over-ride the treatment algorithm on the basis of clinical judgment. Reasons for any departure from the algorithm were recorded. Patients were permitted access to the clinic nurse throughout the study, and where necessary additional clinical visits were arranged.

\section{Study measurements at each visit}

FENO was measured according to current guidelines ${ }^{19}$ using a NIOX MINO electrochemical analyser ${ }^{20-22}$ or a NIOX chemiluminescence analyser (both Aerocrine, Solna, Sweden). The latter was available at the Research Unit, $5 \mathrm{~km}$. from the Health Centre, but was used only when there was technical failure of the NIOX MINO. To validate FENO results, the sensors from the NIOX MINO device were tested against a calibrated standard, and where appropriate, a correction factor was applied to take account of signal drift. Spirometry 
RS Hewitt et al.

Figure 1. Decision algorithm in relation to compliance with ICS treatment, FENO levels and asthma control.

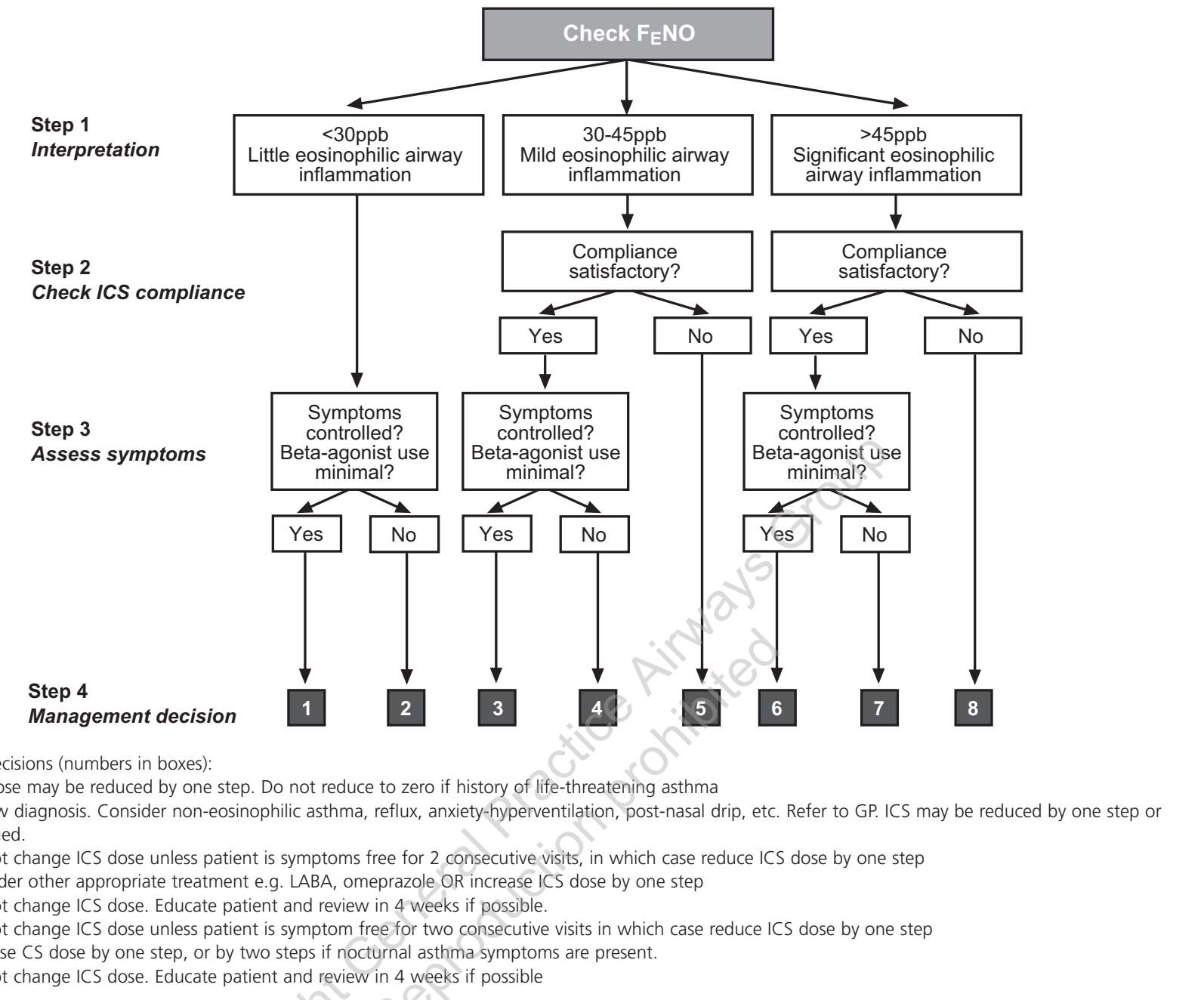

was performed according to accepted standards using a Spiro USB spirometer (Micro Medical, Kent, England).

The study received ethical approval from the Lower South Island Ethics Committee, and each participant gave written informed consent. Each GP participated in a start-up meeting, but thereafter further directions regarding the conduct of the study were not given.

\section{Analysis}

The primary study end-point was asthma control, recorded as yes/no for well-controlled asthma. The secondary study endpoint was the dose of ICS at each visit and over the 12-month follow-up interval. Comparisons were made between ICS use during the 12 months prior to study entry for those patients who were not steroid-naïve, using individual prescription and pharmacy records. All doses of ICS are reported as fluticasone equivalent, where $1 \mathrm{mcg}$ fluticasone is equivalent to $2 \mathrm{mcg}$ of beclomethasone or budesonide. Clinical decisions made at each study visit were retrospectively assessed by JOC and DRT independently of the nurse (CMM) and GPs who undertook day-to-day study monitoring, after the last patient had finished the study. Statistical analysis was by paired t-tests and analysis of variance as appropriate. The proportions of patients with well-controlled asthma at each study visit were compared using McNemar's test.

\section{Results}

One hundred and thirty-one patients were entered into the study. Of these 14 did not wish to be treated with inhaled corticosteroids, six subsequently withdrew consent, 23 did not attend for follow-up, four developed other medical conditions, four were deemed to have a respiratory condition other than asthma, and two had asthma which was too unstable to permit further participation. Thus, 78 patients with a diagnosis of asthma completed the study. Their baseline data are summarised in Table 2 .

\section{Asthma control}

The proportion (\%) of patients with controlled and uncontrolled asthma at each study visit, stratified by steroid 
Table 2. Baseline data. Asthma control (yes/no) was determined according to the "Three Questions" questionnaire (15). $F E V_{1}=$ forced expiratory volume in one second; ICS = inhaled corticosteroid; LABA = long acting beta-agonist.

\begin{tabular}{lc} 
Parameter & \\
\hline$n$ & 78 \\
\hline Sex (Male:Female) & $39: 39$ \\
\hline Mean age (years, range) & $42(11-75)$ \\
\hline Ex-smokers & $19(24.4 \%)$ \\
\hline Prior use of ICS $(n)$ & 56 \\
\hline LABA use at entry & $14(18 \%)$ \\
\hline FEV 1 \% predicted & $83.6($ SD 21.9$)$ \\
\hline Poorly controlled asthma at entry & $46(59 \%)$
\end{tabular}

use at visit 1, is shown in Table 3. Overall, there was a significant reduction in the number of patients with uncontrolled asthma between visit 1 and visit $5(p=0.0013$ ). Between individual visits the change was significant only between visit 1 and visit 2 ( $p=0.002)$; thereafter the betweenvisit changes were not statistically significant. Only two patients required a total of three courses of oral prednisone during the study.

\section{ICS use}

Twenty-two patients (28.2\%) were not receiving ICS at the time of entering the study. In those who were taking ICS and for whom full pre-study data were available $(n=48)$, the calculated mean daily dose of ICS during the 12 months prior to study entry, based on prescription and pharmacy records, was $352 \mathrm{mcg} /$ day (fluticasone equivalent) [95\% C.I.: 303, 402]. Over the entire 12-month study interval the mean daily dose in these 48 patients was 269 mcg/day [95\% C.I.: 209, 330; $p=0.006]$. The mean daily dose at the final study visit in these same patients ( $n=48$ ) was $195 \mathrm{mcg} /$ day [95\%C.I.: 146, 243; $p<0.001$ for comparison with 12 months prior to study entry].

For all 78 patients the mean daily fluticasone dose over the 12-month study interval was $267 \mathrm{mcg} /$ day [95\% C.I.: 219 ,
Figure 2. Mean dose of fluticasone or equivalent ( $\mu \mathrm{g} / \mathrm{day})$ at each study visit. The data are stratified into those who were steroid naïve at study entry ( $n=22$; squares) and those who were already receiving inhaled corticosteroid therapy ( $n=56$; circles).

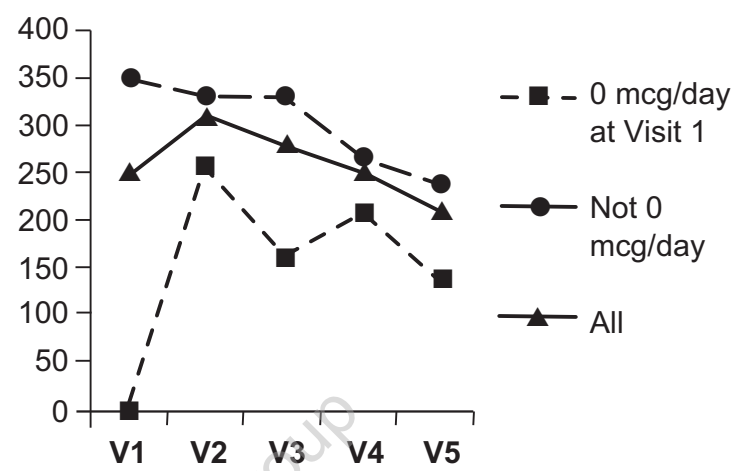

314]. There was a progressive decrease in ICS dose requirements throughout the study, from a maximum of 312 $\mathrm{mcg} /$ day at visit $2[95 \%$ C.I.: 253,371$]$ to $211 \mathrm{mcg} /$ day at visit 5 [95\%C.I.: 165, 258]. The reduction in fluticasone dose over time was highly significant $(p=0.022)$ (see Figure 2$)$. Four patients discontinued ICS treatment altogether without adverse effect.

\section{Subgroup analyses: high $\mathrm{F}_{\mathrm{E}} \mathrm{NO}$}

There were 39 patients whose $\mathrm{FENO}_{\mathrm{E}}$ was high at visit 1 $(>45 \mathrm{ppb})$. The $\mathrm{FENO}_{\mathrm{E}}$ remained high at visits $2,3,4$, and 5 , in $15,15,13$ and 16 patients, respectively, although in only four patients were the $\mathrm{FENO}_{\mathrm{N} O}$ levels $>45 \mathrm{ppb}$ on all five occasions. The changes in mean ICS dose requirements and asthma control at each visit for these patients are shown in Table 4.

The mean reduction in $\mathrm{F}_{\mathrm{E}} \mathrm{NO}$ in patients whose $\mathrm{F}_{\mathrm{E}} \mathrm{NO}$ was $>45 \mathrm{ppb}$ at any visit who went from poor control to good control at the next visit (and for whom complete data were available; $\mathrm{n}=29$ ) was $49.3 \mathrm{ppb}[95 \% \mathrm{C.I.:} 27.1,71.4]$, equivalent to a reduction in $\mathrm{F}_{E} \mathrm{NO}$ of $35.2 \%$ [95\%:C.I.: 13.0, 57.4]. On the other hand, on those occasions when $\mathrm{FENO}_{\mathrm{E}}$ was high and asthma was poorly controlled at that visit as well as at the subsequent visit

Table 3. Proportion of patients with well controlled asthma at each study visit. The study population is further stratified into those who were taking $(n=56)$ or not taking $(n=22)$ inhaled corticosteroid treatment at study entry. $P$ values are for the significance of the change between visit 1 and visit 5.

\begin{tabular}{|c|c|c|c|c|c|c|}
\hline & Visit 1 & Visit 2 & Visit 3 & Visit 4 & Visit 5 & $\mathrm{p}$ \\
\hline All patients $(n=78)$ & $41.0 \%(32 / 78)$ & $72.7 \%(48 / 66)$ & $53.5 \%(38 / 71)$ & $75.8 \%(50 / 66)$ & $67.6 \%(50 / 74)$ & 0.001 \\
\hline $\begin{array}{l}\text { Not taking ICS treatment } \\
\text { at study entry }(n=22)\end{array}$ & $9.1 \%(2 / 22)$ & $79.0 \%(15 / 19)$ & $65.0 \%(13 / 20)$ & $77.8 \%(14 / 18)$ & $60.0 \%(12 / 20)$ & 0.002 \\
\hline $\begin{array}{l}\text { Taking ICS at study } \\
\text { entry }(n=56)\end{array}$ & $53.6 \%(30 / 56)$ & $70.2 \%(33 / 47)$ & $49.0 \%(25 / 51)$ & $75.0 \%(36 / 48)$ & $70.4 \%(38 / 54)$ & 0.072 \\
\hline
\end{tabular}


Table 4. Changes in ICS dose and asthma control in those patients who had a high FENO (>45ppb) at visit 1 (n=39). These data do not include patients whose FENO was $>45 \mathrm{ppb}$ for the first time at visit 2 to 5 inclusive. Figures in brackets are $95 \%$ confidence intervals. * This included 18 patients whose ICS dose at visit 1 was zero.

\begin{tabular}{lccccc} 
& Visit 1 & Visit 2 & Visit 3 & Visit 4 & Visit 5 \\
\hline $\begin{array}{l}\text { Number with FENO>45ppb at } \\
\text { visit 1, with follow-up numbers }\end{array}$ & 39 & 34 & 35 & 33 & 36 \\
\hline Mean FEN (ppb) & $101.4[86.6,116.1]$ & $54.9[42.0,67.9]$ & $50.3[41.0,59.6]$ & $44.8[35.6,54.0]$ & $59.5[46.9,72.1]$ \\
\hline ICS dose (mcg/day) & $182 *[116,248]$ & $352[260,444]$ & $332[231.434]$ & $311[221,402]$ & $246[168,323]$ \\
\hline Asthma not controlled $(\%)$ & $69.2(27 / 39)$ & $26.5(9 / 34)$ & $42.7(15 / 35)$ & $21.2(7 / 33)$ & $38.9(14 / 36)$
\end{tabular}

Table 5. Changes in ICS dose and asthma control in those patients who had a low FENO (<30ppb) at visit 1. Figures in brackets are $95 \%$ confidence intervals.

\begin{tabular}{lccccc} 
& Visit 1 & Visit 2 & Visit 3 & Visit 4 & Visit 5 \\
\hline N & 23 & 19 & 21 & 22 & 22 \\
\hline Mean FENO (ppb) & $21.3[19.0,23.5]$ & $31.6[21.6,41.5]$ & $23.6[17.1,30.1]$ & $25.7[20.0,31.4]$ & $26.8[19.7,33.8]$ \\
\hline ICS dose (mcg/day) & $376[303,448]$ & $206[125,287]$ & $227[144,310]$ & $190[125,255]$ & $159[96,221]$ \\
\hline Asthma not controlled (\%) & $30.4(7 / 23)$ & $26.3(5 / 19)$ & $42.9(9 / 21)$ & $31.8(7 / 22)$ & $22.7(5 / 22)$
\end{tabular}

$(\mathrm{n}=10)$, the mean reduction in FENO was less: $20.7 \mathrm{ppb}[95 \% \mathrm{C.I.:}$ $5.0,36.4]$, equivalent to $24.1 \%[3.9,44.3]$.

\section{Subgroup analyses: low FENO}

There were 23 patients who had low FENO at visit 1 (<30ppb). The changes in asthma control and mean ICS dose requirements at each visit for these patients are shown in Table 5. Of the 23 , only seven (30.4\%) had poorly controlled asthma at visit 1 . The number of patients with low FENO increased during the study to 27,30,33 and 32, at visits 2, 3, 4 , and 5, respectively. FENO remained low throughout the study interval in only six. The mean reduction in $\mathrm{F}_{\mathrm{E}} \mathrm{NO}$ in patients whose FENO was <30ppb at any visit and who went from poor control to good control at the next visit (and for whom complete data were available; $n=22$ ) was $2.2 \mathrm{ppb}$ [95\%C.I.: -1.4, 5.8], equivalent to 5.4\% [95\%:C.I.: -9.2 , 20.1], suggesting that factors other than airway inflammation

Table 6. Direction of dose adjustment for ICS on those occasions when the decision made was not what was prescribed by the treatment algorithm.

\begin{tabular}{lc}
$\begin{array}{l}\text { Inappropriate decision making } \\
\text { regarding ICS dose }\end{array}$ & $\begin{array}{c}\mathrm{N} \\
\text { (total }=90)\end{array}$ \\
\hline Should have been reduced but was not & $30(33.3 \%)$ \\
\hline Should have been increased but was not & $17(18.9 \%)$ \\
\hline Should have remained unchanged but was reduced & $10(11.1 \%)$ \\
\hline Should have remained unchanged but was increased & $26(28.9 \%)$ \\
\hline Unclear & $7(7.8) \%$
\end{tabular}

were responsible for the poor asthma control status.

\section{Clinical decisions}

There were 355 formal decision points in relation to the management algorithm during the study. Of these, 90 were discrepant $(25.4 \%)$ - i.e. the decision made departed from the decision prescribed by the treatment algorithm - of which $23(25.6 \%)$ were independently deemed to have been appropriate and 67 (74.4\%) were considered inappropriate. Based on the clinical notes, these decisions were further classified and are reported in Table 6. The over-riding factors are listed in Table 7. The proportion of inappropriate decisions occurring in association with a high or low FENO did not differ (15.3\% and $19.3 \%$, respectively).

Table 7. Over-riding factors which operated at 90 decision points when the decision made was not what was prescribed by the treatment algorithm, arranged by category.

\begin{tabular}{lcc} 
Decision & Appropriate & Inappropriate \\
\hline Trend issues: falling $\mathrm{F}_{\mathrm{E} N O}$ & 2 & 0 \\
\hline Trend issues: rising $\mathrm{F}_{\mathrm{E} N}$ & 4 & 3 \\
\hline Safety concerns & 5 & 13 \\
\hline $\begin{array}{l}\text { Confounding by external decision } \\
\text { making }\end{array}$ & 0 & 30 \\
\hline Patient preference, unspecified & 1 & 12 \\
\hline Compliance issues & 2 & 5 \\
\hline Indeterminate & 9 & 4 \\
\hline Total & 23 & 67
\end{tabular}




\section{Discussion}

In this open, uncontrolled study in a primary care setting, the use of a treatment algorithm based on $\mathrm{F}_{\mathrm{E}} \mathrm{NO}$ measurements resulted in an overall increase in the number of patients with well-controlled asthma (from $40 \%$ to $70 \%$ approximately). Although the magnitude of the change was greatest in the steroid-naive group and was achieved during the first three months of treatment, it was still identifiable in the steroidtreated group, although this was of borderline statistical significance. Regression to the mean may have influenced these trends. However, the improved asthma control also coincided with a progressive reduction in the dose of ICS, notably in patients already being prescribed ICS treatment (a $44.6 \%$ fall). The magnitude of effect for these outcomes is similar to those previously reported in a blinded randomised controlled trial. ${ }^{6}$ Although achieving well-controlled asthma in approximately $70 \%$ of patients may seem less than ideal, our results are similar to those in the so-called GOAL study in which $60-70 \%$ of patients achieved well-controlled asthma using a treatment strategy involving progressive step-up in ICS dose. $^{23}$ Thus, the use of the present algorithm appeared to achieve clinical benefits, and the primary aim of the study was fulfilled.

However, the interpretation of these results needs to be cautious. Deliberately, there was no control group; therefore, it is possible that the positive outcomes did not result from using the FENO-based protocol per se but from increased contact between patients and the asthma nurse specialist. The level of support provided had not previously been offered i.e. consultations prior to study entry were patient-initiated. In two recent studies investigating the effectiveness of $\mathrm{F}_{\mathrm{E}} \mathrm{NO}^{7,10}$ the impact of frequent contact with health professionals was highlighted as the likely reason for improved outcomes. In the study by Szefler et al. ${ }^{7}$ in which adolescents with poorly controlled asthma received intensive education and support, most of the improvement in asthma control was achieved during the run-in. Depending on the measured outcome, the impact of nurse-led clinics compared to usual care is variable, ${ }^{24-27}$ suggesting that at least in part, the present results were attributable to using the $\mathrm{F}_{\mathrm{E}} \mathrm{NO}$-based protocol rather than simply increased contact with a health care professional. At the very least, it was our experience that FENO measurements provided patients with more specific understanding of their asthma, often prompting a willingness to accept the diagnosis and the need for regular antiinflammatory therapy.

$\mathrm{F}_{\mathrm{E} N O}$-based treatment algorithms have varied with respect to $F_{E} N O$ cut-points; some have been two-tiered ${ }^{6,8}$ and others have been three-tiered ${ }^{8,9}$ or multi-tiered. ${ }^{7}$ In the present study, a three-tiered approach was adopted with cut-points of $30 \mathrm{ppb}$ and $45 \mathrm{ppb}$. In our view, design features other than the
Difficulties Reluctance by clinicians to reduce or withdraw inhaled steroids despite objective evidence highlighting the appropriateness of doing so. This confounded the application of the treatment algorithm based on a biomarker. Alternative methods The positive outcomes contained within this and other studies point to the benefits of regular patient contact with a nurse practitioner as a means of improving asthma outcomes

New questions Further studies are needed to explore whether there are specific subgroups of patients with asthma in whom the use of a biomarker is particularly helpful, for example obese patients with asthma.

Lessons Human behaviour and habits are as important as new technology in the management of disease.

cut-points for $\mathrm{F}_{\mathrm{E}} \mathrm{NO}$ are more important in determining the efficacy of such algorithms. Firstly, the starting point for decision-making is critical. In the study by Szefler et al., decision-making was based firstly on symptom assessment and thereafter FENO measurements were added - and conferred no benefits. ${ }^{7}$ In that study and the one reported by De Jongste et al., ${ }^{10}$ low FENO measurements were invariably "trumped" by symptoms, and in such circumstances no ICS dose reduction was possible. In the present study, the starting point for decision-making was the FENO level (high, low or intermediate) followed by attention to clinical symptoms (see Figure 1). Low FENO levels were acted upon even when symptoms were present (Figure 1; decision point no.2). Additionally, our algorithm also included treatment directives which went beyond adjusting the dose of ICS (e.g. decision point no.2: reconsider the diagnosis; and no.3: consider other treatment e.g. long-acting beta-agonist). This broader approach was considered important in the context of a "real world" study and may have contributed to better outcomes.

The study design was deliberately open, and permitted the algorithm decisions to be over-ridden by the GP. Somewhat surprisingly the frequency of these events was high: treatment decisions differed from what was specified at approximately $25 \%$ of the decision points (90/355). Of these 90 decisions, $25 \%(23 / 90)$ were considered to be appropriate. On the remaining occasions (67/90) when over-riding factors were considered to have been applied inappropriately, the reasons for doing so were variable (see Table 7$)$. The majority (43/67, $64 \%$ ) appeared to reflect a lack of confidence in relation to reducing the ICS dose, either on the part of the GP or the patient (designated "safety concerns", "confounding by external decision making"). On $62.3 \%$ of these 67 occasions the ICS dose should have been reduced but was left unchanged or should have remained unchanged but was increased. This may have been because the algorithm decision 
appeared counterintuitive or even risky. Concerns about the risks of reducing the ICS dose especially in a symptomatic patient also appear to have influenced the design of other studies. ${ }^{7,11}$ However, data show that the predictive value of a low $\mathrm{F}_{\mathrm{E} N O}$ for subsequent loss of control with steroid dose reduction is high. ${ }^{28}$ This message does not appear to have carried much weight. We concede that although the protocol violations in our study may have reduced the overall benefits of using $\mathrm{FENO}_{E}$, it was unrealistic to expect the rigors of a randomised trial to be applied in day-to-day practice. In fact, despite the frequency of these "violations" a reduction in mean ICS dose was still achieved without compromising asthma control.

In a previous study, it was stated that "normalising" FENO is not possible in patients whose baseline FENO value is high. ${ }^{29}$ Our results confirm that this is the case: among those with high $\mathrm{F}_{\mathrm{E} N O}$ at visit 1, only four patients had subsequent values which were consistently lower than the cut-point of $45 \mathrm{ppb}$. However, as seen in Table 4, despite consistently high levels at visits 2 to 5 , in the majority of this subgroup asthma control was still achieved despite decreasing doses of ICS. This confirms that net changes in $\mathrm{FENO}_{\mathrm{E}}$ in individual patients are more important than absolute values in relation to a specific cut-point. The magnitude of changes in $\mathrm{FENO}_{\mathrm{E}}$ associated with improvement in asthma control status was similar to that reported by Michils et al..$^{30}$ In that study, the reduction in FENO associated with improved control was $40 \%$ or greater: in the present study it was 35.2\% [95\%C.I.:13.0, 57.4].

In summary, we have evaluated a decision-support algorithm for asthma management based on $F_{E N O}$ measurements using a portable nitric oxide analyser ${ }^{20-22}$ in primary care. The proportion of patients with poorly controlled asthma decreased, while simultaneously there was a progressive reduction in ICS dose requirements. The results may have been enhanced by regular contact with the asthma nurse. On the other hand, the benefits were obtained despite relatively frequent protocol "violations". The outcomes obtained in patients with persistently high FENO levels suggest that fixed cut-points for $\mathrm{F}_{\mathrm{E}} \mathrm{NO}$ are less likely to be helpful than individually determined optimum changes. Although the weight of evidence in the literature does not support routine use of $\mathrm{F}_{\mathrm{ENO}}$ to optimise asthma therapy, measuring $\mathrm{F}_{\mathrm{ENO}} \mathrm{N}$ levels enables factors other than airway inflammation to be identified in patients with ongoing symptoms, and this can now be done easily in primary care.

\section{Acknowledgements}

The authors wish to thank the patients of the Mornington Health Centre for their participation in this study. They also acknowledge the active contribution of the nurses and doctors of the Health Centre including Eric Bradfield, Tony Fitchett, John Greaves, Elaine Harvey, Sharleen Johnston, Jenny Lewis, Tim Medlicott, Peter Radue, Niranjan Sharma, Barry Turner, and Jonathan Woolrych. The study was funded through a Strategic Initiative Grant of the Dunedin School of Medicine (2005) and an unrestricted grant from Aerocrine $A B$, Solna, Sweden. The nitric oxide analysers were provided by Aerocrine, Solna, Sweden. Dr Hewitt was in receipt of the Tony Hocken Medical Research Fellowship of the Dunedin School of Medicine.

\section{Conflict of interest declarations}

The researchers received a grant of $\$ 25,000$ from Aerocrine AB, Solna, Sweden, a manufacturer of nitric oxide analysers to conduct this study. DRT has received lecture fees of $\$ 2000$ from Aerocrine $A B$, Solna, Sweden.

\section{References}

1. Taylor DR, Pijnenburg MW, Smith AD, De Jongste JC. Exhaled nitric oxide measurements: clinical application and interpretation. Thorax 2006;61(9):81727. http://dx.doi.org/10.1136/thx.2005.056093

2. Pizzichini E, Pizzichini MM, Gibson P, et al. Sputum eosinophilia predicts benefit from prednisone in smokers with chronic obstructive bronchitis. Am J Respir Crit Care Med 1998;158(5 Pt 1):1511-17.

3. Meijer RJ, Postma DS, Kauffman HF, Arends LR, Koeter GH, Kerstjens HA. Accuracy of eosinophils and eosinophil cationic protein to predict steroid improvement in asthma. Clin Exp Allergy 2002;32(7):1096-103. http://dx.doi.org/10.1046/j.1365-2222.2002.01412.x

4. Hahn PY, Morgenthaler TY, Lim KG. Use of exhaled nitric oxide in predicting response to inhaled corticosteroids for chronic cough. Mayo Clin Proc 2007;82(11):1350-5. http://dx.doi.org/10.4065/82.11.1350

5. Smith $A D$, Cowan JO, Brassett KP, et al. Exhaled nitric oxide: a predictor of steroid response. Am J Respir Crit Care Med 2005;172(4):453-9. http://dx.doi.org/10.1164/rccm.200411-14980C

6. Smith AD, Cowan JO, Brassett KP, Herbison GP, Taylor DR. Use of exhaled nitric oxide measurements to guide treatment in chronic asthma. $N$ Engl J Med 2005;352(21):2163-73. Epub 2005 May 24. http://dx.doi.org/ 10.1056/NEJMoa043596

Szefler SJ, Mitchell H, Sorkness CA, et al. Management of asthma based on exhaled nitric oxide in addition to guideline-based treatment for inner-city adolescents and young adults: a randomised controlled trial. Lancet 2008;372(9643):1065-72. http://dx.doi.org/10.1016/S0140-6736(08)61448-8

8. Shaw DE, Berry MA, Thomas M, et al. The use of exhaled nitric oxide to guide asthma management: a randomized controlled trial. Am J Respir Crit Care Med 2007;176(3):231-7. http://dx.doi.org/10.1164/rccm.200610-14270C

9. Pijnenburg MW, Bakker EM, Hop WC, De Jongste JC. Titrating steroids on exhaled nitric oxide in children with asthma: a randomized controlled trial. Am J Respir Crit Care Med 2005;172(7):831-6. http://dx.doi.org/10.1164/ rccm.200503-4580C

10. De Jongste JC, Carraro S, Hop WC, Baraldi E. Daily Telemonitoring of Exhaled Nitric Oxide and Symptoms in the Treatment of Childhood Asthma. Am J Respir Crit Care Med 2008;179:93-7. http://dx.doi.org/10.1164/rccm. 200807-10100C

11. Green RH, Brightling CE, McKenna $S$, et al. Asthma exacerbations and sputum eosinophil counts: a randomised controlled trial. Lancet 2002;360(9347):171521. http://dx.doi.org/10.1016/S0140-6736(02)11679-5

12. Jayaram L, Pizzichini MM, Cook RJ, et al. Determining asthma treatment by monitoring sputum cell counts: effect on exacerbations. Eur Respir $J$ 2006;27(3):483-94. http://dx.doi.org/10.1183/09031936.06.00137704

13. Gruffydd-Jones K, Ward S, Stonham C, Macfarlane TV, Thomas M. The use of exhaled nitric oxide monitoring in primary care asthma clinics: a pilot study. Prim Care Resp J 2007;16(6):349-56. http://dx.doi.org/ 10.3132/pcrj.2007.00076

14. McSharry CP, McKay IC, Chaudhuri R, Livingston E, Fraser I, Thomson NC. Short and long-term effects of cigarette smoking independently influence exhaled nitric oxide concentration in asthma. J Allergy Clin Immunol 2005;116(1):8893. http://dx.doi.org/10.1016/j.jaci.2005.03.025 
Exhaled nitric oxide measurements in primary care

15. Pearson M. Measuring clinical outcomes in asthma: a patient-focused approach. Royal College of Physicians Report 1999.

16. Thomas M, Gruffydd-Jones K, Stonham C, Ward S, Macfarlane TV. Assessing asthma control in routine clinical practice: use of the Royal College of Physicians '3 Questions'. Prim Care Resp J 2009;18(2):83-8. http://dx.doi.org/10.3132/pcrj.2008.00045

17. Pijnenburg MW, Hofhuis W, Hop WC, De Jongste JC. Exhaled nitric oxide predicts asthma relapse in children with clinical asthma remission. Thorax 2005;60(3):215-18. http://dx.doi.org/10.1136/thx.2004.023374

18. Kharitonov SA, Gonio F, Kelly C, Meah S, Barnes PJ. Reproducibility of exhaled nitric oxide measurements in healthy and asthmatic adults and children. Eur Respir J 2003;21(3):433-8. http://dx.doi.org/10.1136/thx.2004.023374

19. ATS/ERS Recommendations for Standardized Procedures for the Online and Offline Measurement of Exhaled Lower Respiratory Nitric Oxide and Nasal Nitric Oxide, 2005. Am J Respir Crit Care Med 2005;171(8):912-30. http://dx.doi.org/10.1164/rccm.200406-71

20. Khalili B, Boggs PB, Bahna SL. Reliability of a new hand-held device for the measurement of exhaled nitric oxide. Allergy 2007;62(10):1171-4. http://dx.doi.org/10.1111/j.1398-9995.2007.01475.x

21. Alving K, Janson C, Nordvall L. Performance of a new hand-held device for exhaled nitric oxide measurement in adults and children. Respir Res 2006;7:67. http://dx.doi.org/10.1186/1465-9921-7-67

22. Menzies D, Nair A, Lipworth BJ. Portable exhaled nitric oxide measurement: Comparison with the "gold standard" technique. Chest 2007;131(2):410-14. http://dx.doi.org/10.1378/chest.06-1335

23. Bateman ED, Boushey HA, Bousquet J, et al. Can guideline-defined asthma control be achieved? The Gaining Optimal Asthma ControL study. Am J Respir Crit Care Med 2004;170(8):836-44. http://dx.doi.org/10.1164/rccm.200401$0330 \mathrm{C}$

24. Fay JK, Jones A, Ram FS. Primary care based clinics for asthma. Cochrane Database Syst Rev 2002(1):CD003533.

25. Kamps AW, Brand PL, Kimpen JL, et al. Outpatient management of childhood asthma by paediatrician or asthma nurse: randomised controlled study with one year follow up. Thorax 2003;58(11):968-73.

26. Newcomb P. Results of an asthma disease management program in an urban pediatric community clinic. J Spec Pediatr Nurs 2006;11(3):178-88. http://dx.doi.org/10.1111/j.1744-6155.2006.00064.x

27. Heard AR, Richards IJ, Alpers JH, Pilotto LS, Smith BJ, Black JA. Randomised controlled trial of general practice based asthma clinics. Med J Aust 1999;171(2):68-71.

28. Zacharasiewicz A, Wilson N, Lex C, et al. Clinical use of noninvasive measurements of airway inflammation in steroid reduction in children. Am J Respir Crit Care Med 2005;171(10):1077-82. Epub 2005 Feb 11. http://dx.doi.org/10.1164/rccm.200409-12420C

29. Pijnenburg MW, Bakker EM, Lever S, Hop WC, De Jongste JC. High fractional concentration of nitric oxide in exhaled air despite steroid treatment in asthmatic children. Clin Exp Allergy 2005;35(7):920-5. http://dx.doi.org/10.1111/j.1365-2222.2005.02279.x

30. Michils A, Baldassarre S, Van Muylem A. Exhaled nitric oxide and asthma control: a longitudinal study in unselected patients. Eur Respir J 2008,31(3):539-46. http://dx.doi.org/10.1183/09031936.00020407

\section{Available online at http://www.thepcrj.org}

